\title{
Erratum to: Leaching behavior of arsenite and arsenate from the contaminated sediment by the effect of phosphate ion under anaerobic conditions
}

\author{
Md. Abul Hashem • Kei Toda $\cdot$ Shin-Ichi Ohira
}

Published online: 28 February 2015

(C) Springer-Verlag Berlin Heidelberg 2015

\section{Erratum to: Environ Earth Sci}

\section{DOI 10.1007/s12665-015-4078-3}

In the original publication the authors would like to correct the error in the name of the third author.

The correct name of the third author should be Shin-Ichi Ohira.

The online version of the original article can be found under doi:10.1007/s12665-015-4078-3.

Md. Abul Hashem · K. Toda · S.-I. Ohira

Department of Chemistry, Kumamoto University,

Kurokami 2-39-1, Kumamoto 860-8555, Japan

Md. Abul Hashem ( $)$

Department of Leather Engineering, Khulna University of Engineering and Technology (KUET), Khulna 9203, Bangladesh

e-mail: mahashem@mail.kuet.ac.bd; hashem_518@yahoo.com 